\title{
Concise Total Synthesis and Stereochemical Assignment of (-)-Psychotridine.
}

\author{
Tony Z. Scott, Vinicius F. Armelin, and Mohammad Movassaghi*
}

Department of Chemistry, Massachusetts Institute of Technology, Cambridge, Massachusetts 02139, United States

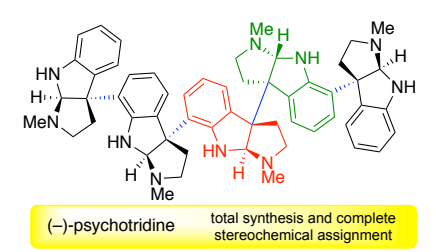

\begin{abstract}
We report the first enantioselective total synthesis and stereochemical assignment of (-)-psychotridine. Application of our diazene-directed assembly of enantiomerically enriched cyclotryptamines afforded a highly convergent synthesis of the pentameric alkaloid, allowing its detailed structural assignment. Highlights of the synthesis include introduction of four quaternary stereocenters with complete stereochemical control in a single step via photoextrusion of three molecules of dinitrogen from an advanced intermediate and metal-catalyzed $\mathrm{C}-\mathrm{H}$ amination in complex settings.
\end{abstract}

The oligomeric cyclotryptamine alkaloids are a subset of pyrroloindoline natural products comprised of multiple $\mathrm{C}-\mathrm{C}$ linked cyclotryptamine units. ${ }^{1}$ This structurally fascinating family of alkaloids possesses a range of intriguing biological activities, such as analgesic and antifungal properties, and cytotoxicity against human cancer cell lines. ${ }^{1}$ Notably, these alkaloids pose a considerable challenge to chemical synthesis due to the $\mathrm{C} 3 \mathrm{a}-\mathrm{C} 3 \mathrm{a}^{\prime}$ and $\mathrm{C} 3 \mathrm{a}-\mathrm{C}^{\prime}$ linkages, the corresponding C3a-quaternary stereocenters on each cyclotryptamine subunit, and the presence of multiple basic nitrogen atoms. While several polycyclotryptamine alkaloids have been prepared through chemical synthesis using innovative strategies, ${ }^{2,3}$ other complex members with unknown stereochemistry have not been accessed. ${ }^{1 f, 4}$ The pentameric alkaloid (-)-psychotridine (4), ${ }^{4}$ first isolated from an extract of Psychotria beccaroides in 1974, inhibits aggregation of washed isolated human platelets, exhibits cytotoxicity against HTC rat hepatocellular carcinoma cells, and displays dose-dependent reduction of capsaicin-induced pain via a non-opioid pathway. ${ }^{5}$ Despite being the subject of biological studies and commercially available, ${ }^{6}(-)$-psychotridine (4) has no stereochemical assignment and it is depicted without absolute or relative stereochemistry in the literature. ${ }^{4.5}$ Herein, we report the first total synthesis and complete stereochemical assignment of (-)psychotridine (4). The application of our diazene-directed assembly of enantiomerically enriched cyclotryptamines ${ }^{3,7,8}$ led to a highly convergent synthesis of the pentameric alkaloid $\mathbf{4}$, allowing its detailed structural assignment. 

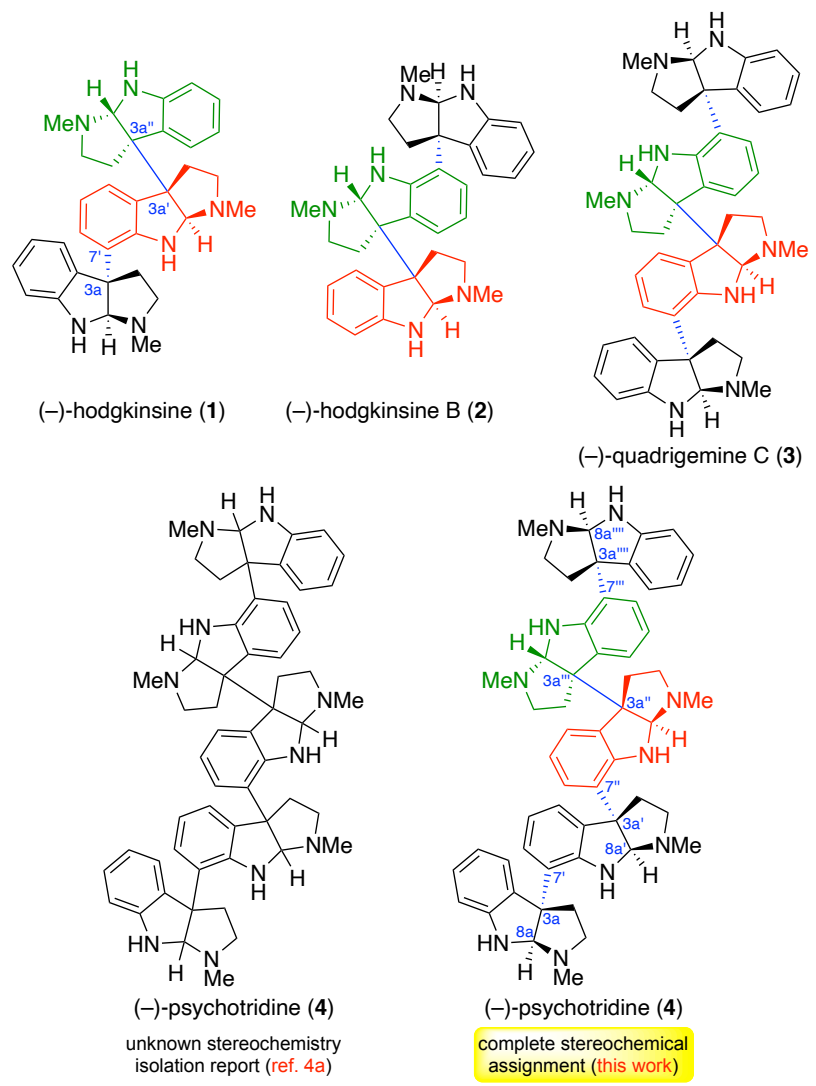

Figure 1. Representative cyclotryptamine alkaloids. 
Scheme 1. Retrosynthetic analysis of (-)-psychotridine (4).
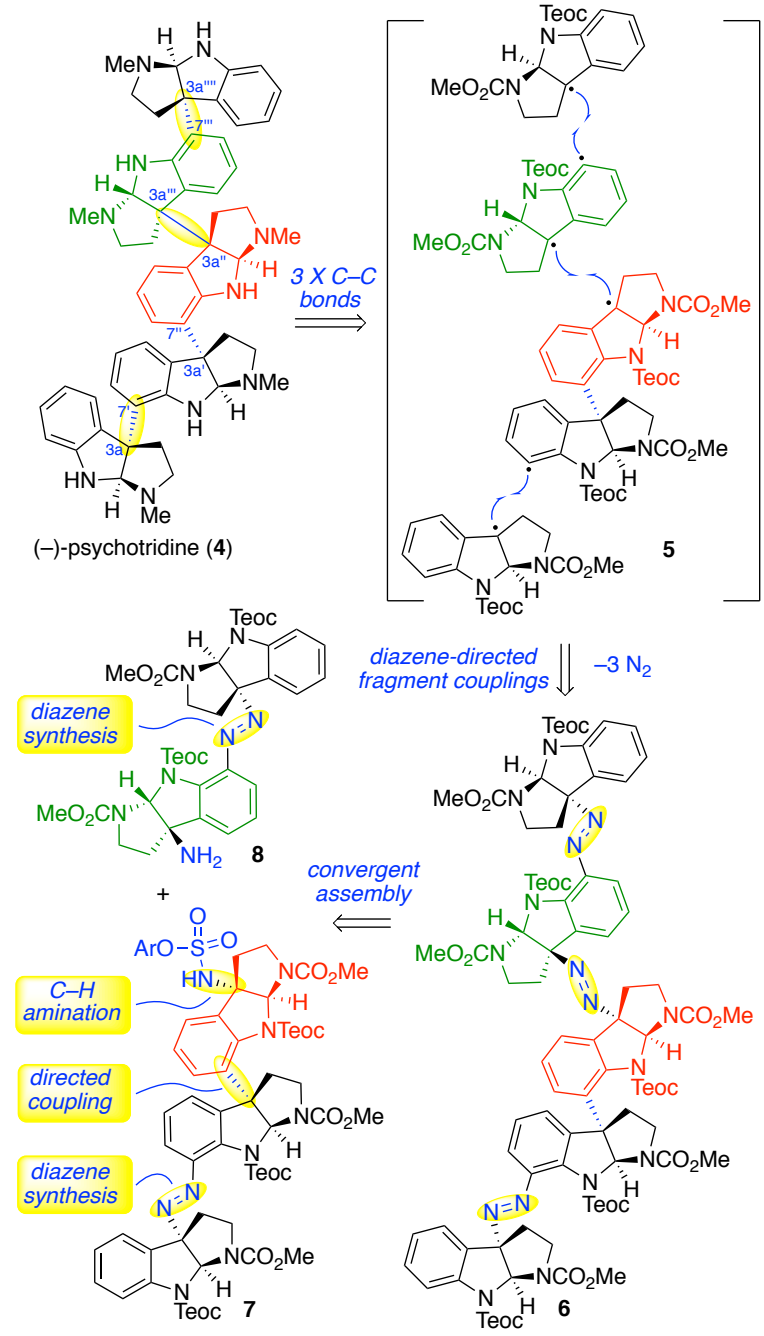

$\begin{gathered}\text { diazene-directed } \\ \text { fragment couplings }\end{gathered}-3 \mathrm{~N}_{2}$
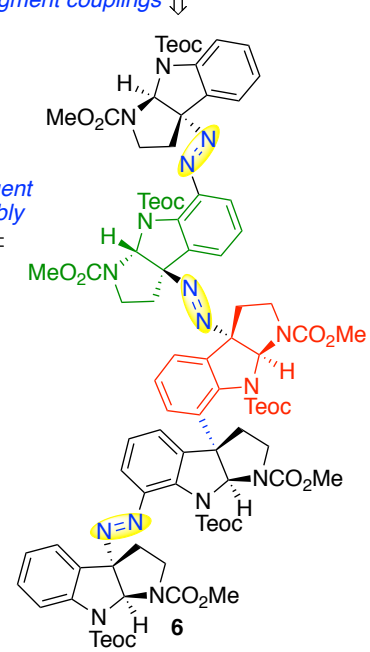

While many polycyclotryptamines contain a $\mathrm{C} 3 \mathrm{a}(\mathrm{Csp} 3)-\mathrm{C} 3 \mathrm{a}^{\prime}(\mathrm{Csp} 3)$ linkage that unites a single cyclotryptamine with a larger fragment with repeating $\mathrm{C} 3 \mathrm{a}(\mathrm{Csp} 3)-\mathrm{C}^{\prime}(\mathrm{Csp} 2)$ linkages (Figure 1, alkaloids $\mathbf{1}$ and 2), a subset of these alkaloids contain a

$\mathrm{C} 3 \mathrm{a}(\mathrm{Csp} 3)-\mathrm{C} 3 \mathrm{a}^{\prime}(\mathrm{Csp} 3)$ linkage that combines a dimeric fragment with an equal or larger fragment (Figure 1, alkaloids 3 and 4$) .{ }^{\text {If }}$ While the stereochemistry of (-)-psychotridine (4) was not assigned, its structure was reported to be consistent with a pentameric cyclotryptamine alkaloid with a $\mathrm{C} 3 \mathrm{a}(\mathrm{Csp} 3)-\mathrm{C} 3 \mathrm{a}^{\prime}(\mathrm{Csp} 3)$ linkage (Figure 1, alkaloid 4) connecting a cyclotryptamine-dimer and a cyclotryptamine-trimer (Figure 1, alkaloid 4). Examination of the naturally occurring trimeric alkaloids (-)-hodgkinsine (1) and (-)hodgkinsine B (2) along with the related tetrameric alkaloid (-)-quadrigemine C (3) reveals alkaloids $\mathbf{1}$ and $\mathbf{2}$ as substructures of alkaloid 3 (Figure 1). This led to our hypothesis that (-)-quadrigemine C (3) may be a substructure of (-)-psychotridine (4), leading to our identification of the $\left(3 \mathrm{a} R, 3 \mathrm{a}^{\prime} R, 3 \mathrm{a}\right.$ " $R, 3 \mathrm{a}$ "' $S, 3 \mathrm{a}^{\prime \prime \prime \prime} R, 8 \mathrm{a} R, 8 \mathrm{a}^{\prime} R, 8 \mathrm{a}$ " $R, 8 \mathrm{a}$ '" $\left.S, 8 \mathrm{a}^{\prime \prime \prime} R\right)$-stereoisomer out of 32 possible stereoisomers of alkaloid 4 (Figure 1) as the most promising candidate and the target of our synthetic studies.

Our retrosynthetic analysis for (-)-psychotridine (4) is illustrated in Scheme 1. We anticipated securing all five quaternary stereocenters of the pentameric alkaloid 4 via diazene-directed fragment assembly., ${ }^{3,7}$ We envisioned the completely stereocontrolled formation of four quaternary stereocenters in a single step via the photoextrusion of three molecules of dinitrogen from tris-diazene pentamer $\mathbf{6}$. Tris-diazene pentamer $\mathbf{6}$ could arise from oxidation of a mixed sulfamide, ${ }^{3,8}$ that could be generated through a convergent union of two fragments, trimer sulfamate 7 and dimer amine $\mathbf{8}$. Dimer amine-diazene $\mathbf{8}$ could be prepared in one step from a dimeric C3a-sulfamate ester we have previously accessed. ${ }^{3}$ In turn, trimer sulfamate-diazene 7 could be prepared by derivatization of a dimeric diazene previously prepared in our $(-)$-quadrigemine $\mathrm{C}(3)^{3}$ synthesis via sequential $\mathrm{Ir}$-catalyzed $\mathrm{C}_{\mathrm{sp} 2}-\mathrm{H}$ amination (C7'-N bond formation), diazene synthesis, and a $\mathrm{Rh}$-catalyzed $\mathrm{C}_{\mathrm{sp} 3}-\mathrm{H}$ amination $(\mathrm{C} 3 \mathrm{a}$ "- $\mathrm{N}$ bond formation). Importantly, the versatility of our diazene-directed assembly of cyclotryptamine fragments combined with the plausible connective homology of alkaloids 3 and $\mathbf{4}$ could allow rapid access to the pentameric alkaloid $\mathbf{4}$ from key intermediates accessed in our synthesis of the tetrameric alkaloid 3 . 
Scheme 2. Synthesis of diazene trimer sulfamate (-)-7.

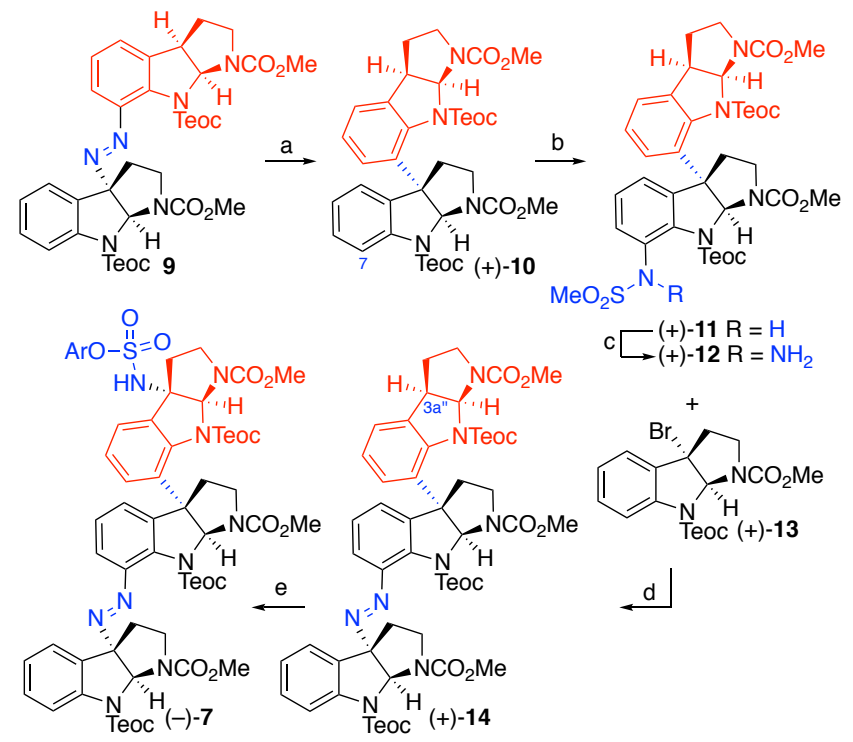

Reagents and conditions: (a) $h v(300 \mathrm{~nm}) 25^{\circ} \mathrm{C}, 71 \%$; (b) $\mathrm{MeSO}_{2} \mathrm{~N}_{3},\left[\mathrm{Cp}^{*} \mathrm{IrCl}_{2}\right]_{2}, \mathrm{AgNTf}_{2}, \mathrm{AgOAc}, \mathrm{ClCH}_{2} \mathrm{CH}_{2} \mathrm{Cl}, 23{ }^{\circ} \mathrm{C}, 72 \%$; $(\mathrm{c})$ $\mathrm{NaH}$, THF, $0{ }^{\circ} \mathrm{C} ; \mathrm{Ph}_{2} \mathrm{P}(\mathrm{O}) \mathrm{ONH}_{2}, 23{ }^{\circ} \mathrm{C}, 86 \%$; (d) AgOTf, DTBMP, $23{ }^{\circ} \mathrm{C}, 68 \%$; (e) 2,6-difluorophenyl sulfamate, $\mathrm{Rh}_{2}\left(\right.$ esp) ${ }_{2}$, $\mathrm{Ph}(\mathrm{Me})_{2} \mathrm{CCO}_{2} \mathrm{H}, \mathrm{PhI}(\mathrm{OAc})_{2}, \mathrm{MgO}, 5 \AA \bullet \mathrm{MS}, i$-PrOAc, $22{ }^{\circ} \mathrm{C}, 22 \mathrm{~h}, 37 \%$ (66\% BRSM). Ar = 2,6-difluorobenzene.

Synthesis of key fragment (-)-7 commenced from diazene-dimer 9, an intermediate we have previously prepared via our singlestep aryl-alkyl diazene synthesis involving silver-promoted coupling of readily available C3a-bromocyclotryptamine and C7hydrazidocyclotryptamine monomers. ${ }^{3}$ Photolysis of diazene 9 as a thin film with $300 \mathrm{~nm}$ light afforded the C3a'-C7" dimer $(+)-10$ in 71\% yield. ${ }^{9}$ Exposure of dimer (+)-10 to dichloro(pentamethylcyclopenta-dienyl)iridium (III) dimer (10 mol\%) and methanesulfonyl azide under optimal conditions, ${ }^{3,10}$ afforded the dimeric sulfonamide $(+)-\mathbf{1 1}$ in $72 \%$ yield as a single regioisomer. Treatment of sulfonamide $(+)-\mathbf{1 1}$ with sodium hydride and $O$-(diphenylphosphinyl)hydroxylamine provided the desired nucleophilic dimer hydrazide $(+)-12$ in $86 \%$ yield. Portionwise addition of silver(I) trifluoromethanesulfonate to a mixture of hydrazide $(+)-12$ and bromide $(+)$-13 (2.5 equiv) directly delivered diazene trimer $(+)-14$ in $68 \%$ yield, representing one of the most challenging applications of our direct aryl-alkyl diazene synthesis in complex settings. ${ }^{3}$ Treatment of trimer $(+)-\mathbf{1 4}$ to Rh-catalyzed intermolecular $\mathrm{C} 3 \mathrm{a}-\mathrm{H}$ amination, ${ }^{11}$ stopping the reaction at half conversion to minimize undesired double amination side products, afforded the trimeric sulfamate (-)-7 in 37\% yield with 44\% yield of recovered trimer $(+)-14(66 \%$ yield based on recovered starting material). The selective amination of the $\mathrm{C} 3 \mathrm{a}^{\prime \prime}-\mathrm{H}$ methine of trimer $(+)-\mathbf{1 4}$ over its three activated $\mathrm{C} 2$ methylenes afforded the necessary precursor for convergent assembly of the key diazene intermediate $\mathbf{6}$ (Scheme 1). 
Scheme 3. Total synthesis of (-)-psychotridine (4).
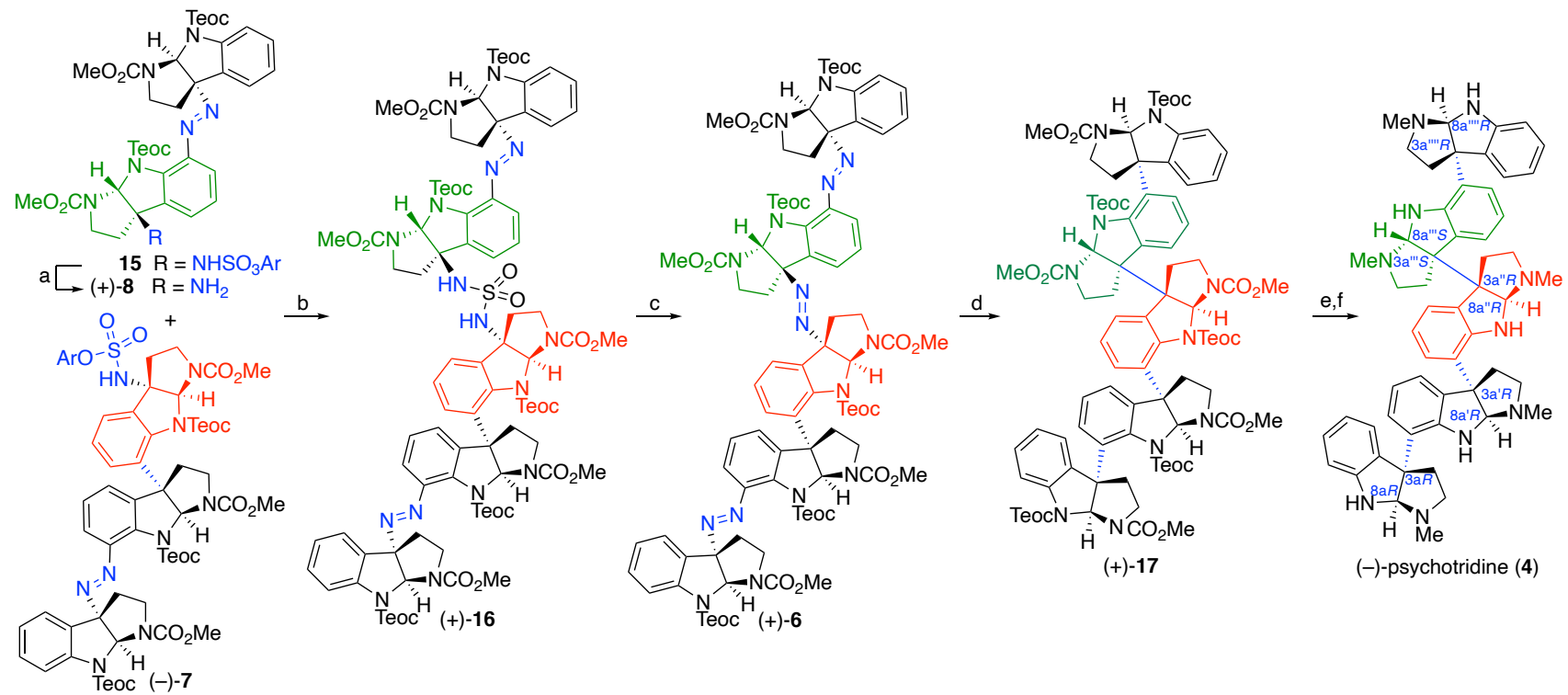

Reagents and conditions: (a) pyridine, $\mathrm{MeCN}-\mathrm{H}_{2} \mathrm{O}, 70{ }^{\circ} \mathrm{C}, 89 \%$; (b) DMAP, THF, $23{ }^{\circ} \mathrm{C}$, 83\%. (c) 1,3-dichloro-5,5dimethylhydantoin, 1,8-diazabicyclo[5.4.0] undec-7-ene, $\mathrm{MeOH}, 23{ }^{\circ} \mathrm{C}, 83 \%$; (d) $h v(300 \mathrm{~nm}), 25{ }^{\circ} \mathrm{C}, 58 \%$; (e) TBAF, THF, $23{ }^{\circ} \mathrm{C}$, $87 \%$; (f) $\mathrm{EtNMe}_{2} \cdot \mathrm{AlH}_{3}, \mathrm{PhMe}, 65^{\circ} \mathrm{C}, 65 \%$.

Hydrolysis of the sulfamte ester $\mathbf{1 5},{ }^{3}$ prepared in two-steps from cyclotryptamine derivatives, provided the dimeric amine $(+)-\mathbf{8}$ in $89 \%$ yield. Treatment of trimeric sulfamate $(-)-7$ with dimeric amine $(+)-8$ (1.2 equiv) in the presence of $4-(\mathrm{N}, \mathrm{N}-$ dimethylamino)pyridine (DMAP, 2.4 equiv) gave the mixed pentameric sulfamide $(+)-16$ in $83 \%$ yield. Oxidation of the sulfamide (+)-16 with 1,3-dichloro-5,5-dimethylhydantoin (DCDMH) in the presence of 1,8-diazabicyclo[5.4.0] undec-7-ene (DBU) in methanol $^{8}$ furnished the tris-diazene pentamer $(+)-6$ in 77\% yield, setting the stage for our planned diazene-directed and completely stereocontrolled fusion of all cyclotryptamine fragments. In the event, irradiation of tris-diazene pentamer $(+)-6$ as a thin film with 300 $\mathrm{nm}$ light for $8 \mathrm{~h}$ delivered fully $\mathrm{C}-\mathrm{C}$ linked cyclotryptamine pentamer $(+)-17$ in $58 \%$ yield as a single diastereomer. Significantly, the desired product results from the cleavage of six $\mathrm{C}-\mathrm{N}$ bonds, extrusion of three molecules of dinitrogen, the formation of three $\mathrm{C}-\mathrm{C}$ bonds, and completely stereocontrolled formation of four quaternary stereocenters. Unveiling of the five indoline nitrogens by treatment of the pentamer $(+)-\mathbf{1 7}$ with tetrabutylammonium fluoride followed by exhaustive methyl carbamate reduction using alane-dimethylethylamine complex ${ }^{3}$ gave (-)-psychotridine (4) in $57 \%$ yield over two steps. All spectroscopic data and the optical rotation (observed $[\alpha]_{\mathrm{D}}^{23}=-31\left(\mathrm{c}=0.51, \mathrm{CHCl}_{3}\right)$; lit.: $\left.[\alpha]_{\mathrm{D}}=-38\left(\mathrm{c}=1, \mathrm{CHCl}_{3}\right)\right)$ for our synthetic $(-)$-psychotridine $(4)$ were consistent with literature values. ${ }^{4}$ Furthermore, we purchased ${ }^{6}$ and analyzed a natural sample of (-)-psychotridine (4) from Psychotria lyciflora to acquire more detailed set of ${ }^{1} \mathrm{H}$ and ${ }^{13} \mathrm{C}$ NMR data for comparison with our synthetic (-)-psychotridine (4). ${ }^{9}$ Based on the consistency of the data for our synthetic (-)-psychotridine (4) and both the available literature data and the additional data we obtained for a natural sample of (-)-psychotridine (4), ${ }^{9}$ we assigned the structure of (-)-psychotridine (4) as the $\left(3 \mathrm{a} R, 3 \mathrm{a}^{\prime} R, 3 \mathrm{a}\right.$ " $R, 3 \mathrm{a}^{\prime \prime} S, 3 \mathrm{a}^{\prime \prime \prime} R, 8 \mathrm{a} R, 8 \mathrm{a}^{\prime} R, 8 \mathrm{a}$ " $R, 8 \mathrm{a}$ "'S,8a'"' $R$ ) pentamer depicted in Figure 1 and Scheme 3.

In summary, we report the first total synthesis of (-)-psychotridine (4). Our synthesis leveraged the modular and directed assembly of stereochemically defined cyclotryptamine monomers to introduce all five quaternary stereocenter with complete absolute and relative stereochemical control. Highlights of the synthesis include introduction four quaternary stereocenters with complete stereochemical control in a single step via photoextrusion of three molecules of dinitrogen from an advanced intermediate and application of Ir- and Rh-catalyzed C-H amination chemistry in complex settings. The hypothesis concerning a common biosynthetic lineage for polycyclotryptamines (-)-2-4 led to our projected stereochemistry for (-)-psychotridine (4). The consistency of the characterization data for our synthetic sample of (-)-psychotridine (4) with available literature data (-)-psychotridine (4), in addtion to comparison with an expanded data set we acquired using a natural sample of psychotridine (4), ${ }^{9}$ confirmed their identical molecular structure, thereby allowing our unambiguous stereochemical assignment of the pentameric alkaloid 4.

\section{ASSOCIATED CONTENT}

\section{Supporting Information}

The Supporting Information is available free of charge.

Experimental procedures, spectroscopic data, and copies of ${ }^{1} \mathrm{H}$, and ${ }^{13} \mathrm{C}$ NMR spectra (PDF). 


\section{AUTHOR INFORMATION}

\section{Corresponding Author}

*Email: movassag@mit.edu

\section{Funding}

We are grateful for financial support from NIH-NIGMS (GM-089732 and GM-141963).

\section{Notes}

The authors declare no competing financial interests.

\section{ACKNOWLEDGMENT}

We thank Dr. Kyan D’Angelo and Katherine Walker, graduate students in the Movassaghi group, for helpful discussions.

\section{REFERENCES}

(1) (a) Cordell, G. A.; Saxton, J. E. The Alkaloids: Chemistry and Physiology; Manske, R. H. F., Rodrigo, R. G. A., Eds.; Academic Press: New York, 1981; Vol. 20, pp 3-295. (b) Hino, T.; Nakagawa, M. The Alkaloids: Chemistry and Pharmacology; Brossi, A., Ed.; Academic Press: New York, 1989; Vol. 34, pp 1-75. (c) Sevenet, T.; Pusset, J. The Alkaloids: Chemistry and Pharmacology; Cordell, G. A., Ed.; Academic Press: New York, 1996; Vol. 48, pp 1-73. (d) Anthoni, U.; Christophersen, C.; Nielsen, P. H. Alkaloids: Chemical and Biological Perspectives; Pelletier, S. W., Ed.; Pergamon: London, 1999; Vol. 13, pp 163-236. (e) Crich, D.; Banerjee, A. Chemistry of the Hexahydropyrrolo[2,3-b]indoles: Configuration, Conformation, Reactivity, and Applications in Synthesis. Acc. Chem. Res. 2007, 40, 151-161. (f) Steven, A.; Overman, L. E. Total Synthesis of Complex Cyclotryptamine Alkaloids: Stereocontrolled Construction of Quaternary Carbon Stereocenters. Angew. Chem., Int. Ed. 2007, 46, 5488-5508. (g) Büschleb, M.; Dorich, S.; Hanessian, S.; Tao, D.; Schenthal, K. B.; Overman, L. E. Synthetic Strategies toward Natural Products Containing Contiguous Stereogenic Quaternary Carbon Atoms. Angew. Chem., Int. Ed. 2016, 55, 4156-4186.

(2) (a) Lebsack, A. D.; Link, J. T.; Overman, L. E.; Stearns, B. A. Enantioselective Total Synthesis of Quadrigemine C and Psycholeine. J. Am. Chem. Soc. 2002, 124, 9008-9009. (b) Overman, L. E.; Peterson, E. A. Enantioselective Total Synthesis of the Cyclotryptamine Alkaloid Idiospermuline. Angew. Chem., Int. Ed. 2003, 42, 2525-2528. (c) Kodanko, J. J.; Overman, L. E. Enantioselective Total Syntheses of the Cyclotryptamine Alkaloids Hodgkinsine and Hodgkinsine B. Angew. Chem., Int. Ed. 2003, 42, 2528-2531. (d) Overman, L. E.; Peterson, E. A. Enantioselective synthesis of (-)-idiospermuline. Tetrahedron 2003, 59, 6905-6919. (e) Kodanko, J. J.; Hiebert, S.; Peterson, E. A.; Sung, L.; Overman, L. E.; de Moura Linck, V.; Goerck, G. C.; Amador, T. A.; Leal, M. B.; Elisabetsky, E. Synthesis of All Low-Energy Stereoisomers of the Tris(pyrrolidinoindoline) Alkaloid Hodgkinsine and Preliminary Assessment of Their Antinociceptive Activity. J. Org. Chem. 2007, 72, 7909-7914. (f) Snell, R. H.; Woodward, R. L.; Willis, M. C. Catalytic Enantioselective Total Synthesis of Hodgkinsine B. Angew. Chem., Int. Ed. 2011, 50, 9116-9119. (g) Canham, S. M.; Hafensteiner, B. D.; Lebsack, A. D.; May-Dracka, M. T.; Nam, S.; Stearns, B. A.; Overman, L. E. Stereocontrolled enantioselective total synthesis of the [2+2] quadrigemine alkaloids. Tetrahedron 2015, 71, 6424-6436. (h) Jamison, C. R.; Badillo, J. J.; Lipshultz, J. M.; Comito, R. J.; MacMillan, D. W. C. Catalyst-Controlled Oligomerization for the Collective Synthesis of Polypyrroloindoline Natural Products. Nat. Chem. 2017, 9, 1165-1169.

(3) Lindovska, P.; Movassaghi, M. Concise Synthesis of (-)-Hodgkinsine, (-)-Calycosidine, (-)-Hodgkinsine B, (-)-Quadrigemine C, and (-)Psycholeine via Convergent and Directed Modular Assembly of Cyclotryptamines. J. Am. Chem. Soc. 2017, 139, 17590-17596.

(4) Hart, N.; Johns, S.; Lamberton, J.; Summons, R. Psychotridine, a $\mathrm{C}_{55} \mathrm{H}_{62} \mathrm{~N}_{10}$ Alkaloid From Psychotria beccarioides (Rubiaceae). Aust. J. Chem. 1974, 27, 639-646.

(5) (a) Beretz, A.; Roth-Georger, A.; Corre, G.; Kuballa, B.; Anton, R.; Cazenave, J. P. Polyindolinic alkaloids from Psychotria forsteriana. Potent inhibitors of the aggregation of human platelets. Planta Med. 1985, 51, 300-303. (b) Roth, A.; Kuballa, B.; Bounthanh, C.; Cabalion, P.; Sévenet, T.; Beck, J. P.; Anton, R. Cytotoxic activity of polyindoline alkaloids of Psychotria forsteriana (Rubiaceae). Planta Med. 1986, 52, 450-453. (c) Amador, T. A.; Verotta, L.; Nunes, D. S.; Elisabetsky, E. Involvement of NMDA receptors in the analgesic properties of psychotridine. Phytomedicine 2001, 8, 202-206.

(6) (a) Cayman Chemical No. 31645. (b) Bioaustralis fine chemicals No. BIA-P1968.

(7) Movassaghi, M.; Ahmad, O. K.; Lathrop, S. P. Directed Heterodimerization: Stereocontrolled Assembly via Solvent-Caged Unsymmetrical Diazene Fragmentation. J. Am. Chem. Soc. 2011, 133, 13002-13005.

(8) For applications of diazene-directed complex-fragment assembly in total synthesis, see: (a) Lathrop, S. P.; Movassaghi, M. Application of diazenedirected fragment assembly to the total synthesis and stereochemical assignment of (+)-desmethyl-meso-chimonanthine and related heterodimeric alkaloids. Chem. Sci. 2014, 5, 333-340. (b) Lathrop, S. P.; Pompeo, M.; Chang, W.-T. T.; Movassaghi, M. Convergent and Biomimetic Enantioselective Total Synthesis of (-)-Communesin F. J. Am. Chem. Soc. 2016, 138, 7763-7769. (c) Pompeo, M. M.; Cheah, J. H.; Movassaghi, M. Total Synthesis and Anti-Cancer Activity of All Known Communesin Alkaloids and Related Derivatives. J. Am. Chem. Soc. 2019, 141, 14411-14420.

(9) See Supporting Information for details.

(10) Xu, L.; Tan, L.; Ma, D. Iridium(III)-Catalyzed Regioselective C7-Amination of N-Pivaloylindoles with Sulfonoazides. J. Org. Chem. 2016, 81, $10476-10483$.

(11) Roizen, J. L.; Zalatan, D. N.; Du Bois, J. Selective Intermolecular Amination of C-H Bonds at Tertiary Carbon Centers. Angew. Chem., Int. Ed. 2013, 52, 11343-11346. 